\title{
Crystal Structure of Tricyclohexyltin 2,2,3,3- Tetramethylcyclopropanecarbocylate
}

\author{
Xueqing Song and George Eng* \\ Department of Chemistry and Physics, University of the District of Columbia, Washington, DC, \\ 20008, USA Gengraudc.edu
}

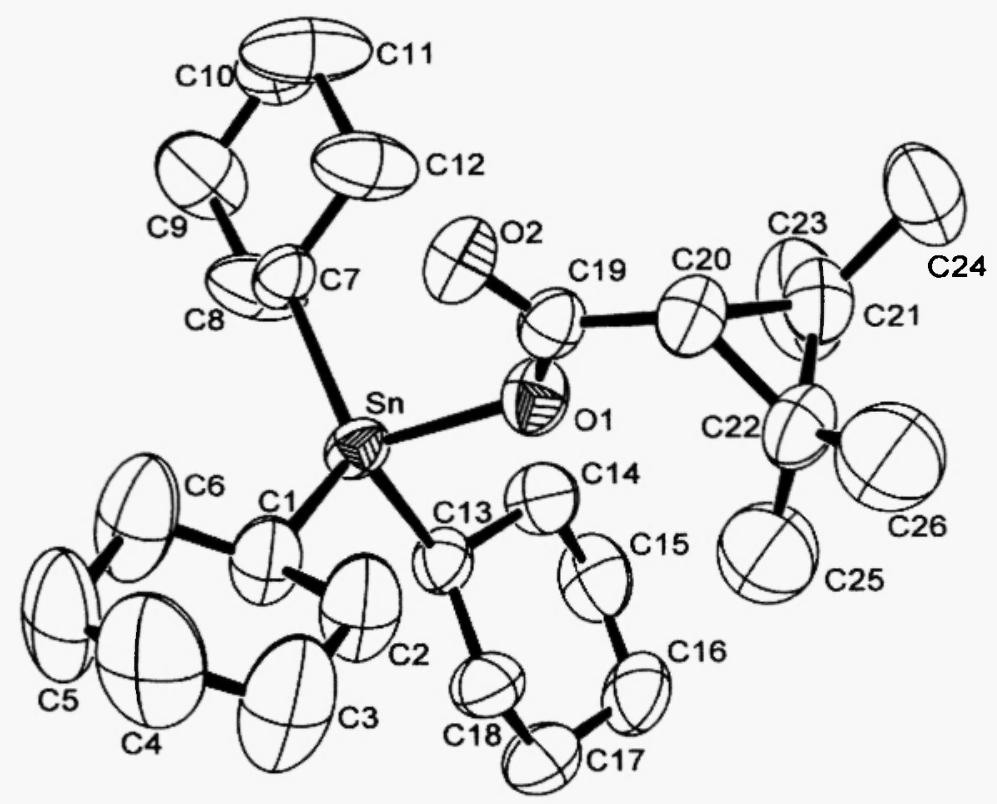

Figure 1: Molecular structure of $\left[\mathrm{Cy}_{3} \mathrm{SnO}_{2} \mathrm{CC}_{3} \mathrm{H}\left(\mathrm{CH}_{3}\right)_{4}\right]$. Key geometric parameters: $\mathrm{Sn}-\mathrm{Ol} 2.111$ (2), SnCl 2.159(4), Sn-C7 2.164(3), Sn-C13 2.148(3), C19-Ol 1.305(4), C19-O2 1.226(4) Aं; Cl-Sn-C7 123.02(14). Cl-Sn-C13 112.67(15), C7-Sn-C13 116.01(13), Ol-Sn-Cl 101.80(13), Ol-Sn-C7 103.82(12), Ol-Sn-C13 92.47(11), H-atoms omitted for clarity.

\section{COMMENT}

Triorganotins / $-3 /$ and pyrethroids /4/ have been shown to be effective insecticides against mosquito larvae as well as adult mosquitoes. In an attempt to synthesize a more effective insecticide, a precursor of the acid moiety of pyrethroid, 2,2,3,3-tetramethyl cyclopropane carboxylic acid, was incorporated into a tricyclohexyltin molecule. It is hoped that the "designed" molecule will exhibit synergistic effects in its activity. The crystal structure analysis for tricyclohexyltin 2,2,3,3-tetramethylcyclopropanecarboxylate indicated that the molecule is monomeric with a distorted tetrahedral geometry as shown in Fig. 1. The tin 
atom is coordinated to the carboxylate group via one of the oxygen atoms forming a $\mathrm{Sn}-\mathrm{O}(\mathrm{l})$ bond of 2.111 (2) $\AA$. The other $\mathrm{Sn}-\mathrm{O}$ bond distances are over $3 \AA$ indicating that no other significant interactions exist between these two atoms. However, the second $\mathrm{O}$ atom of the carboxylate group may have a steric influence and contribute to the distorted tetrahedral geometry of the molecule. The observed $\mathrm{Sn}-\mathrm{O}$ value is similar to those found for other tricyclohexyltin carboxylates such as tricyclohexyltin 2-(p-chlorophenyl)-3methylbutyrate $/ 5 /$, 4-hydroxybenzoate $/ 6 /$ and 2-[(E)-2-(2-hydroxy-5-methylphenyl)-1- diazenyl] benzoate 171.

\section{EXPERIMENTAL}

Tricyclohexyltin hydroxide $(5 \mathrm{mmol})$ was added, with stirring, to $50 \mathrm{~mL}$ of toluene. To this solution was added 2,2,3,3-tetramethylcyclopropanecarboxylic acid $(5 \mathrm{mmol})$. The mixture was then refluxed for $1 \mathrm{~h}$. A Dean-Stark trap was used to remove the water formed. The toluene was then removed under vacuum and a clear oil was obtained. A white solid formed upon refrigeration overnight. The solid was then dissolved in 95\% ethanol, and upon slow evaporation, crystals suitable for $\mathrm{X}$-ray diffraction analyses were obtained, $\mathrm{mp}$ $72-74{ }^{\circ} \mathrm{C}$. The crystallographic analysis was done at the $\mathrm{X}$-ray Structural Characterization Laboratory in the Chemistry Department at the University of Massachusetts, Amherst.

Table 1

Crystal data for Tricyclohexyltin 2,2,3,3-tetramethylcyclopropanecarboxylate

\begin{tabular}{|c|c|c|c|}
\hline Formula & $\mathrm{C}_{26} \mathrm{H}_{46} \mathrm{O}_{2} \mathrm{Sn}$ & Formula weight & 509.32 \\
\hline Crystal system & Monoclinic & Crystal size, mm & $0.50 \times 0.40 \times 0.40$ \\
\hline Space group & $P 2 / c$ & a, $\AA$ & $10.3984(1)$ \\
\hline $\mathrm{b}, \overline{\mathrm{A}}$ & $11.5462(1)$ & $c, \hat{A}$ & $22.5738(3)$ \\
\hline$\beta, "$ & $99.7754(5)$ & $\mathrm{V}$ & $2670.90(5)$ \\
\hline $\mathrm{Z}$ & 4 & Diffractometer & Nonius Kappa CCD \\
\hline Temperature & $293(2)$ & $\mu(\mathrm{Mo}-\mathrm{K} \alpha), \mathrm{cm}^{-1}$ & 9.74 \\
\hline $\mathrm{D}_{\text {cald }}, \mathrm{g} \mathrm{cm}^{-3}$ & 1.267 & $\mathrm{~F}(000)$ & 1072 \\
\hline$\theta_{\max }^{\circ}$ & 27.53 & Reflns unique & 6067 \\
\hline $\begin{array}{l}\text { Reflns with } I \geq \\
2 \sigma(1)\end{array}$ & 5046 & No. parameter & 252 \\
\hline Weighting scheme & $\begin{array}{l}1 /\left[\sigma^{2}\left(F_{o}^{2}\right)+(0.0457 P)^{2}+3.1616 P\right] \\
P=\left(F_{o}^{2}+2 F_{c}^{2}\right) / 3\end{array}$ & $\begin{array}{l}\text { Goodness of fit } \\
\rho, e \dot{A}^{\cdot 3}\end{array}$ & $\begin{array}{l}1.027 \\
0.781\end{array}$ \\
\hline R (all data) & $\mathrm{R} 1=0.0497, \mathrm{wR} 2=0.1066$ & Final R $[1>2 \sigma(\mathrm{I})]$ & $\begin{array}{l}\mathrm{R} 1=0.0399 \\
\mathrm{wR} 2=0.1002\end{array}$ \\
\hline Programs used & \multicolumn{3}{|c|}{ SHELXS-86 /8/, SHELXL-97/9/ and ORTEP /10/ } \\
\hline Deposition number & CCDC 246577 & & \\
\hline
\end{tabular}




\section{ACKNOWLEDGEMENT}

Financial support from the National Institute of Health Minority Biomedical Research Support Program (MBRS/SCORE, GM08005) is gratefully acknowledged.

\section{REFERENCES}

I. G. Eng, C. Whitmyer, B. Sina and N. Ogwuru, Main Group Met. Chem., 22, 311 (1999).

2. N. Ogwuru, Q. Duong, X. Song and G. Eng, Main Group Met. Chem., 24, 775, (2001).

3. G. Eng, X. Song, Q. Duong, D. Strickman, J. Glass and L. May, Appl. Organometal. Chem.. 18, 363 (2004).

4. R. J. Cremlyn, Agrochemicals Preparation and Mode of Action, John Wiley \& Sons, Chichester, West Sussex, England, 1991; p. 53 and references therein.

5. X. Song, C. Cahill and G. Eng, Appl. Organomet. Chem., 17, 743 (2003).

6. X. Song, C. Cahill and G. Eng, Main Group Met. Chem., 25, 703 (2002).

7. R. Willem, I. Verbruggen, M. Gielen, M. Biesemans, B. Mahieu, T. S. B. Baul and E. R. T. Tiekink. Organometallics, 17, 5758 (1998).

8. G. M. Sheldrick, Acta Crystallogr., A46, 467 (1990).

9. G. M. Sheldrick, SHELXL-97: Program for Crystal Structure Refinement, University of Gottingen, 1997.

10. C. K. Johnson, ORTEP, Report ORNL-5138, Oak Ridge National Laboratory, TN, USA, 1976. 
